COMMENT

\title{
The COVID-19 effect on the Paris agreement
}

John M. Reilly (1) ${ }^{1 凶}$, Y.-H. Henry Chen (1) ${ }^{1} \&$ Henry D. Jacoby (1) ${ }^{1}$

The pandemic and efforts to control it are causing sharp reductions in global economic activity and associated fossil energy use, with unknown influence on longer-term efforts to limit greenhouse gas emissions under the Paris Climate Agreement. To explore this effect, estimates of economic recession and recovery in near-term months are extended to cover a return to full employment in future years, to be compared with an estimate of growth had COVID-19 not occurred. On the assumption that the Paris emissions pledges for 2020 will be met in any case, projection of global emissions with and without the pandemic show that, through its growth impact alone, it will yield only a small effect on emissions in 2030 and beyond. Other COVID legacies may include residual influences in patterns of consumption and travel, and the direction of recovery funds to low carbon investments. Most important, however, will be the effect of the economic shocks on the willingness of nations to meet (or augment) their existing Paris emissions pledges. The main effect of the pandemic on the threat of climate change, therefore, will be not its growth impact but its influence on national commitments to action.

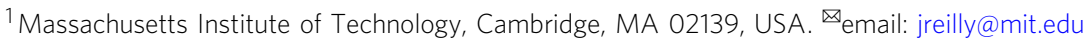




\section{Introduction}

he pandemic will have longer-term effects on society, economy, and environment, and one important legacy will be its influence on the global effort to control human influence on the climate. The current focus of that effort is the 2015 Paris Climate Agreement, and the emissions control pledges that nations have made under its rules and procedures. Termed Nationally Determined Contributions or NDCs, they specify emissions reduction targets to be attained, for most countries, by 2030 (United Nations, 2020). The Agreement includes an update of pledges on a five-year schedule, so it specifies that, in the fall 2020 meeting of its parties, they were to convey the results of a review of their initial NDCs, with the hope of an increase in ambition. The first effect of the pandemic has been the postponing until fall 2021 of this important step in the Paris process.

That one consequence of COVID-19 is clear. Its other effects are highly uncertain. The global recession, now under way, and the pace of recovery over months and years, will influence the emissions-producing activities of all nations, quite apart from actions driven by Paris targets. Moreover, the experience of social distancing and closing of businesses will leave a legacy of changes in patterns of demand and associated energy use. Compounding the uncertainty is the possibility of subsequent waves of infection, imposing further damage on economies. These effects will weigh on national intentions to meet their current NDCs, and to increase ambition in 2021.

The pandemic's effect on overall economic activity. An impression of the influence of the pandemic, through its impact on economic activity alone, can be gained by comparing our earlier analysis at pre-pandemic growth expectations (Reilly et al., 2018) with one attempting to take account of the recession and projected recovery. Of course, both of these economic futures are uncertain, so projecting the ultimate depth of the recession and the path to recovery calls for special humility. Still, we can explore COVID-19 effects by extending analyses of its near-future impact to later years.

We start with a May estimate by the Congressional Budget Office of a 5.6\% U.S. GDP loss in 2020 and $+4.2 \%$ gain in 2021, and the associated unemployment (U.S. Congressional Budget Office, 2020a). Despite the fluidity of the situation, a September CBO update, of -5.9 and $+4.8 \%$, is not substantially different (U.S. Congressional Budget Office, 2020b). This projected recovery in 2021 still leaves economic activity below its level at the end of 2019, and without the pandemic recession the U.S. may have grown another 4 to $5 \%$ percent over these two years. With efforts to reopen the economy in the 2nd and 3rd quarters of 2020, the employment has increased, but the gain in succeeding quarters is expected to be smaller. As a result, the CBO shows employment at the end of 2021 that is still more than 6\% below "full" employment (i.e., the employment rate at the end of 2019).

Assuming this estimate of the initial shock, we estimate the path by which the economy may return to full employment over a longer term, with its associated GDP and energy effects. We regress an asymptotic function on these $\mathrm{CBO}$ estimates (employment $=a+b(1 / t)+$ error), where " $t$ " is quarter of year numbered successively to estimate the possible employment effects and consequences for GDP, energy use, and emissions. This formulation yields an asymptote of less than 100, 97.5. We simulate that path of employment through 2030 and then assume a return to full employment starting in 2035. Economic effects continue beyond this period because of lower savings and investment during the recession.

This is a highly simplified extrapolation of just one possible path of the pandemic's initial economic impact and recovery. Much will depend on the progress of the virus and pace of vaccine development and use, and expectations are changing month to month. The U.S. recovery also depends on the fate of additional fiscal measures to limit costs of the downturn. It is an issue that drew the attention of the U.S. Federal Reserve Chairman, who commented that, "Too little support would lead to a weak recovery... household insolvenencies and business bankruptcies would rise, harming the productive capacity of the economy (Powell, 2020). At the very least, however, the expectation that employment effects may continue for a decade or more is not inconsistent with the apparent impacts on employment of financial crises like that in 2008. Many jobs will disappear, picking up new skills takes time, and wages and productivity could remain below pre-crisis levels indefinitely, even if employees return to work.

We simulated this shock to total productivity through the economic model used in our earlier pre-pandemic assessment of the global emissions trajectory (Reilly et al., 2018; Chen et al., 2016). The resulting GDP impact for the U.S. in 2020 is close to that estimated by the CBO. Then, to estimate the global impact we assume the pandemic causes the same total productivity shock elsewhere, with the effects on GDP extending through 2030. Various projections have been made for other regions of the world generally showing a nearly universal drop in GDP from pre-pandemic levels across major economies and regions (Fitch Ratings, 2020; World Bank Group, 2020). The results of our procedure, shown in Fig. 1, show how COVID-19 reduces global GDP through 2035. In 2020 it is lower by $8.2 \%$, which is the sum of the shock of a $5.1 \%$ loss compared to end-2019 and $3.1 \%$ of expected global growth in 2020 that does not occur. By 2035 GDP is within $2 \%$ of where it would have been without the pandemic.

The uncertainty in these estimates is suggested by the World Bank Group projection of the global shock, which shows a central estimate of a $5.2 \%$ drop in 2020 , but summarizes projections of 2020 GDP reduction that range from near 3\% to almost 9\% (World Bank Group, 2020).

To investigate the effect of the growth shock on greenhouse emissions we assume that countries keep their Paris targets even given all the disruption, and that the structure of their economies is not substantially changed by the experience. The effect of the lower GDP on emissions is shown in Fig. 2, which again compares the combined effect of Paris pledges plus COVID-19 recession with emissions under Paris alone. The pandemic, and national responses to mediate its effects, lower 2020 global emissions by $3.4 \%$, and they are still down by about $2 \%$ in 2025 . By 2030 annual emissions have been reduced by only 1\% (The effect is even smaller in 2035, but it should be noted that the figure does not consider the new round of NDCs due in 2025, which will cover post-2030 years.)

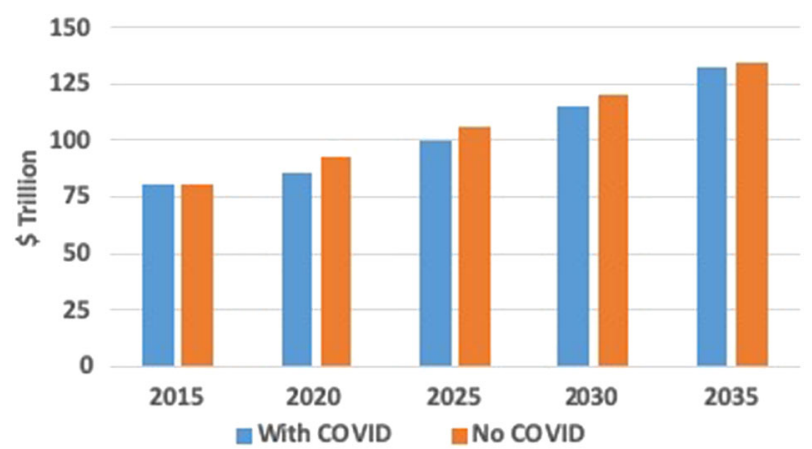

Fig. 1 Covid-19 is estimated to reduce GDP in near decades, though in 2035 it is near its path and there been no pandemic. 


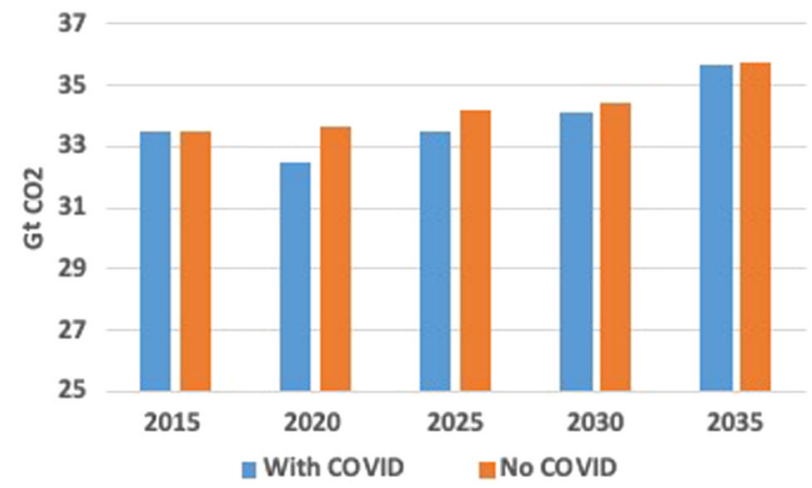

Fig. 2 Assuming nations meet their current pledges under the Paris Climate Agreement the effect of COVID-19, through its effect on GDP, is small in 2020, and negligible in 2030 and beyond.

The effect on 2030 emissions is small because, for the most part, emissions goals under the Paris agreement remain unchanged for most regions. This is the case for countries whose goal is stated relative to an historical emission level; lower future GDP does not change the target, and so has no effect unless the recession drives emissions below the pledged level. Countries with targets against a business-as-usual future may now have a lower BAU and hence meeting the Paris pledge would require a lower absolute emissions reduction. Typically, a country's BAU estimate was submitted with its NDC, however, so unless it is actually revised in response to COVID-19 there will be no effect on emissions. On the other hand, emissions goals of regions with intensity targets (ton $\mathrm{CO}_{2}$ per \$ of GDP) are affected, and those (mainly China) are the reason why, by 2030, emissions including the recession remain below the Paris target. The scenarios without the Paris targets in effect show emissions down $7.4 \%$ in 2020 , and 4.4 and $4.2 \%$ in 2025 and 2030, respectively, as a result of lower GDP resulting from the COVID-19 pandemic.

The human contribution of greenhouse gases to the atmosphere continues throughout the pandemic and its aftermath, of course, only at a slightly less damaging rate for a few years.

Other structural changes that may affect greenhouse gas emissions. The pandemic and governmental and individual responses to it likely will have effects not captured by this estimate of the growth impact alone. Several possibilities merit close watching. First is the possible influence on national efforts to meet their NDCs for 2030, and the anticipated update in the 2021 meeting-responses that will depend to some degree on the form of each pledge. Almost all developed nations pledged an absolute reduction in emissions below those in a 2005 or 1990 base year, and our analysis indicates the pandemic's growth effects will lower the cost of meeting their targets. Many developing countries pledged a percentage reduction in emissions below a business-as-usual (BAU) projection that was presumably associated with a particular growth outlook. If the expected 2030 GDP and associated emissions are now reduced from that underlying the BAU estimate, meeting their current pledges would also become easier.

In a related development, there are calls for directing fiscal stimulous spending to investments in emissions reduction, and to the degree the expenditure is effective the effort to meet 2030 pledges could be further reduced, perhaps encouraging greater commitment (Hanna et al., 2020). The needed large fiscal stimulus and resulting government deficits may also have a legacy effect on growth, as higher tax rates may eventually be required to manage growing national debt. While lower GDP growth is not desirable of itself, we generally observe that a $1 \%$ reduction in GDP reduces emissions on the order of about $0.8 \%$.

Finally, a number of nations, importantly including China and India, pledged a reduction in energy intensity below that in a base year. Our analysis suggests that India's NDC can be met at nearzero cost even without the COVID-19 effect, and that meeting China's $\mathrm{CO}_{2}$ intensity target becomes easier, though the cost is not substantial in either case. Bolstering the prospect that, at least, the pandemic will not discourage countries from taking on deeper cuts are China's pledge to be carbon neutral by 2060, and Europe's plan to reduce emissions by 55\% by 2030 (Guardian, 2020).

Another possible COVID-19 legacy is a change in economic structure, not captured by economic analyses, like ours, that are grounded in historical data. The future of the transport sector, a main source of greenhouse emissions, is of particular interest. In the move of work from office to home, businesses and their employees have learned a great deal about the cost and effectiveness of different styles. Also, a residual fear of crowding could have a lasting effect on air travel and urban rapid transit. Less clear but also potentially significant, the disruption of supply chains during the pandemic could lead countries to take measures that will restrain international goods trade. Increased experience with virtual shopping, banking and entertainment could accelerate changes in the service sector, with fewer "brick and mortar" buildings (and lower energy use) but possibly more transportation emissions from delivery services.

What is the potential magnitude of these structural changes? It is very early, and hard to tell whether changes will be permanent or transitory. Or, a reduction in one activity might lead to increases in others that are just as emissions intensive or more so. For example, when a vaccine becomes widely available there could be burst of leisure travel from those tired of being stuck at home. And, already in the U.S. we have seen a boom in sales of camper vehicles that allow people to travel without interacting with others, but with a considerable emissions footprint.

The first step in determining how big these effects might be is to identify the base level of emissions from that activity or sector (Table 1). All private vehicle emissions are only $6 \frac{1}{2} \%$ of 2030 global emissions in our projection, and air travel accounts for 3\%. At the most optimistic for emissions, if private vehicle use were to remain 10 to $30 \%$ below pre-COVID-19 levels the change would translate to a 0.6 to $2 \%$ drop in global emissions, and if air travel remained 50\% below, that might shave off another $1.5 \%$. On the other hand, reduced willingness to commute in crowded public transport, and more delivery services from increased virtual shopping, would lead to higher emissions elsewhere in transport. Perhaps a trend to shorter supply chains could go the other way, and so it is hard to sign the impact on other transport. A move to more virtual commerce could reduce commercial floor space and space condition needs-a 10 to $20 \%$ reduction would seem to be a large impact, but would reduce global emissions by only $1 / 4$ to $1 / 2 \%$.

Another uncertainty is the long-term effect of stimulus spending. Government debt, worldwide, has increased by an estimated $\$ 30$ trillion as countries attempt to counter the economic effects of the pandemic (McKinsey and Co, 2020). Eventually, this will lead to higher taxes or less spending in other areas. If the tax increase is spread over 10 years, the global fiscal correction would require an annual increase of taxes of over $\$ 3$ trillion. Generally, economic studies find that tax rates and economic growth are inversely related (Engen and Skinner, 1996). Raising taxes by this amount in our model reduced global economic activity over the 10 -year period by about $0.7 \%$, and global emissions dropped by less, 0.5 to $0.6 \%$.

Whether attributable to the pandemic, planned fiscal stimulous spending, or other reasons the significant new commitments by Europe and China would far outweigh these other effects. The 


\section{Table 1 Possible direction and strength of structual changes on emissions.}

\begin{tabular}{|c|c|c|}
\hline Hypothesized effect & $\begin{array}{l}\text { Direction and } \\
\text { strength }\end{array}$ & $\begin{array}{l}\text { Base (\% of global emissions in } 2030 \text { without structural change } \\
\text { unless other indicated) }\end{array}$ \\
\hline \multicolumn{3}{|l|}{ Structural change } \\
\hline $\begin{array}{l}\text { Changes in retailing, restaurants, entertainment, } \\
\text { banking, services }\end{array}$ & + & $2 \frac{1}{2} \%$ (all emissions from the service sector) \\
\hline Remote work, reduced commuting & + & $61 / 2 \%$ (all private vehicle emissions) \\
\hline Less air travel & + & $3 \%$ (all air travel) \\
\hline Changes in public transport, freight, delivery & + or - & $9 \%$ (all other transport) \\
\hline \multicolumn{3}{|l|}{ Emissions pledge/stimulous spending } \\
\hline China and Europe & ++ & $35 \%$ of global emissions \\
\hline Other countries & $?$ & $65 \%$ of global emissoins \\
\hline
\end{tabular}

two regions together account for $35 \%$ of global emissions. There is a question mark as to whether this new level of commitment will spread to other countries, but a willingness to commit to further reductions would easily outweigh structural changes from the pandemic.

In the end, these various effects are not completely separable. The effects on economic structure and energy demand, and likely others not yet perceived, will influence emissions reduction policies, and the willingness of nations to undertake more ambitious pledges under the Paris Agreement. This legacy of the pandemic needs to be understood to the degree possible given current uncertainty, to properly inform national climate policy decisions. Still, based on the information available to date, the important climatic effect of COVID-19 is not the short-term reduction in greenhouse gas emissions but its influence on national commitment to action.

Received: 13 July 2020; Accepted: 16 December 2020;

Published online: 18 January 2021

\section{References}

Chen Y-H, Paltsev S, Reilly JM, Morris JF, Babiker MH (2016) Long-term economic modeling for climate change assessment. Econ Model 52(B):867-883

Engen EM, Skinner J (1996) Taxation and economic growth, NBER Working Paper No. 5826 (November)

Fitch Ratings (2020) Global GDP forecast stable as coronavirus disruption eases, 29 June. https://www.fitchratings.com/research/sovereigns/global-gdp-forecaststable-as-coronavirus-disruption-eases-29-06-2020. Accessed 10 Dec 2020

The Guardian (2020) China pledges to become carbon neutral before 2060. https:// www.theguardian.com/environment/2020/sep/22/china-pledges-to-reachcarbon-neutrality-before-2060. Accessed 8 Oct 2020

Hanna R, Yu Y, Victor D (2020) After COVID-19, green investment must deliver jobs to get political traction. Nature 582:178-189

McKinsey and Co (2020) Closing the $\$ 30$ trillion gap: acting now to manage fiscal deficits during and beyond the COVID-19 crisis (July). https://www. mckinsey.com/industries/public-and-social-sector/our-insights/closing-the30-trillion-gap-acting-now-to-manage-fiscal-deficits-during-and-beyondthe-covid-19-crisis\#. Accessed 8 Oct 2020

Powell J (2020) Recent economic developments and the challenges ahead. https:// www.federalreserve.gov/newsevents/speech/powell20201006a.htm. Accessed 10 Dec 2020

Reilly J, Prinn R, Chen Y-H, Sokolov A, Gao X, Schlosser A, Morris J, Paltsev S, Jacoby H (2018) Food-water-energy-climate: perspectives from 2018. https:// globalchange.mit.edu/sites/default/files/newsletters/files/2018-JP-Outlook. pdf. Accessed 9 Dec 2020
United Nations (2020) Nationally determined contributions (NDCs). Under: UN framework convention on climate change. https://unfccc.int/nationallydetermined-contributions-ndcs. Accessed 9 Dec 2020

U.S. Congressional Budget Office (2020a) Interim economic projections for 2020 and 2021, May 2020. https://www.cbo.gov/system/files/2020-05/56351-CBOinterim-projections.pdf. Accessed 9 Dec 2020

U.S. Congressional Budget Office (2020b) The effects of pandemic-related legislation on output, September 2020. https://www.cbo.gov/system/files/2020-09/ 56537-pandemic-legislation.pdf. Accessed 9 Dec 2020

World Bank Group (2020) Global economic prospects, June. https://www. worldbank.org/en/publication/global-economic-prospects. Accessed $10 \mathrm{Dec}$ 2020

\section{Acknowledgements}

This publication was made possible by USEPA grant RD-83587201. Its contents are solely the responsibility of the grantee and do not necessarily represent the official views of the USEPA. Further, USEPA does not endorse the purchase of any commercial products or services mentioned in the publication. The authors also acknowledge general support of the Program Sponsors (https://globalchange.mit.edu/sponsors/current) of the MIT Joint Program on the Science and Policy of Global Change.

\section{Competing interests}

The authors declare no competing interests.

\section{Additional information}

Correspondence and requests for materials should be addressed to J.M.R.

Reprints and permission information is available at http://www.nature.com/reprints

Publisher's note Springer Nature remains neutral with regard to jurisdictional claims in published maps and institutional affiliations.

Open Access This article is licensed under a Creative Commons Attribution 4.0 International License, which permits use, sharing, adaptation, distribution and reproduction in any medium or format, as long as you give appropriate credit to the original author(s) and the source, provide a link to the Creative Commons license, and indicate if changes were made. The images or other third party material in this article are included in the article's Creative Commons license, unless indicated otherwise in a credit line to the material. If material is not included in the article's Creative Commons license and your intended use is not permitted by statutory regulation or exceeds the permitted use, you will need to obtain permission directly from the copyright holder. To view a copy of this license, visit http://creativecommons.org/ licenses/by/4.0/.

(C) The Author(s) 2021 